\title{
Postoperative radiochemotherapy with weekly cisplatin in patients with head and neck cancer Single-institution outcome analysis
}

\author{
M. PALA ${ }^{1, *}$, K. ODRAZKA ${ }^{2}$, P. HOLECKOVA ${ }^{1}$, P. VITEK ${ }^{1}$, J. KUBES ${ }^{1}$, T. PODLESAK ${ }^{3}$, J. KLOZAR ${ }^{4}$, L. PETRUZELKA ${ }^{1}$
}

${ }^{1}$ Institute of Radiation Oncology, University Hospital Na Bulovce, Prague, Czech Republic; $1{ }^{\text {st }}$ Faculty of Medicine, Charles University in Prague, Prague, Czech Republic; ${ }^{2}$ Department of Radiation Oncology, Multiscan \& Pardubice Regional Hospital, Pardubice, Czech Republic; $1^{\text {st }}$ and $3^{\text {rd }}$ Faculty of Medicine, Charles University in Prague, Prague, Czech Republic; Institute for Postgraduate Medical Education, Prague, Czech Republic; ${ }^{3}$ Department of Otorhinolaryngology, University Hospital Na Bulovce, Prague, Czech Republic; ${ }^{4}$ Department of Otorhinolaryngology and Head and Neck Surgery, University Hospital Motol, Prague, Czech republic; $1^{\text {st }}$ Faculty of Medicine, Charles Univesity in Prague, Czech Republic

${ }^{*}$ Correspondence: palamila@tiscali.cz

Received September 7, 2011 / Accepted September 12, 2011

\begin{abstract}
The objective of this study was to evaluate the feasibility, toxicity and efficacy of postoperative radiochemotherapy with weekly cisplatin in locoregionally advanced or high risk head and neck cancer in a single institutional setting.

Patients with head and neck cancer of stage III/IV or patients with insufficient margins of resection were included in the study. Radiotherapy consisted of 70 Gy/ 7 weeks/ 35 fraction after R1/2 resection and 60-64 Gy/ 6-6,5 weeks/ 30-32 fraction after R0 resection, respectively. All patients received concurrent cisplatin $40 \mathrm{mg} / \mathrm{m}^{2}$ weekly.

Between $7 / 2002$ and 12/2008, 100 consecutive patients [WHO $\leq 2$, male to female ratio 84/16, median age 54 years] were treated. Tumors of the oropharynx were the most frequent (49\%) and stage IV was predominant (86\%). 96\% patients received the full radiation treatment as planned, median total tumor dose was $66 \mathrm{~Gy}$. Omission of weekly cisplatin had been occurring frequently, the most frequent reason for its early cessation were hematological toxicities (34\%). Grade 3/4 mucosal toxicity developed in $32 \%$. No death was observed during the treatment. The late toxicities were acceptable, predominantly subcutaneous fibrosis and xerostomia in most of the cases. We recorded six cases of osteonecrosis. Two and half year overall survival, locoregional control, time to progression and disease free survival were $64 \%, 88 \%, 79 \%$ and $59 \%$, respectively.

Postoperative radiochemotherapy with weekly cisplatin is toxic, but tolerable and highly effective in terms of locoregional control and survival. Multivariete analysis revealed that the only prognostic factor for survival was primary surgery at the University centre.
\end{abstract}

Key words: head and neck cancer, postoperative radiochemotherapy, concomitant chemotherapy, cisplatin

Locoregionally advanced disease of head and neck cancer occurs in a significant proportion of patients. The initial treatment approaches for these tumors include primary surgery with postoperative radio(chemo)therapy or primary radiotherapy combined with chemotherapy or with targeted biological therapy. Tendency to recurrences is high and the overall survival remains poor despite aggressive treatment.

Radiochemotherapy is now a standard component of a treatment algorithm in patients with squamous cell carcinoma of the head and neck. A simultaneous application of these treatment modalities offers the opportunity to enhance the effects of radiation and overcome a radioresistance as well as allows elimination of a potential systemic micrometastatic disease. Several meta-analyses have indicated superior locoregional control and overall survival after radiochemotherapy when compared with radiotherapy alone [1-6]. Among drugs used in this setting, cisplatin has been frequently tested. The optimal scheduling of cisplatin and radiation has not been established. Daily low-dose, weekly intermediate-dose or three-week high-dose regimens have all been used. Unfortunately, improvement in a locoregional control and survival is associated with a significant increase in local and systemic toxicities of combined treatment.

In patients with locoregionally advanced but technically resectable tumors, surgical resection at the primary sites with neck dissection followed by postoperative radiotherapy 
remains one of the most commonly employed approaches. However, despite postoperative radiotherapy, approximately $20-30 \%$ of patients still develop a typical locoregional recurrence within 2 years of treatment [7-9]. To improve results of a traditional approach, chemotherapy has been added to surgery and radiotherapy. A sequential approach has failed to improve survival rates [10-12]. Recent randomized trials demonstrated that there was a significant advantage of adding cisplatin concomitantly to a postoperative course of radiation therapy[13-15]. Similar results were reported for postoperative radiochemotherapy with mitomycin C [16-17]. Metaanalysis of randomized trials confirmed the benefit for postoperative radiochemotherapy in locoregional control $(R R=0,59$; $\mathrm{p}<0,00001)$ and overall survival $(\mathrm{RR}=0,80 ; \mathrm{p}=0,0002)$ [18]. Randomized studies usually tested a three-week regimen of cisplatin in the postoperative setting. In contrast, the role of weekly cisplatin has not been adequately studied. A shortening of interval between cycles could allow an elimination of a greater proportion of cells in sensitive phases of the cell cycle as well as a decreasing of formation of radioresistant clones. Only one small randomized trial with weekly cisplatin was published. Bachaud et al. used a flat dose $50 \mathrm{mg}$ of cisplatin weekly for patients with stage III or IV squamous cell carcinoma of the head and neck and a histological evidence of the extracapsular spread in lymph node metastases [19]. In this trial the concomitant use of weekly cisplatin improved locoregional control, disease free survival and overall survival. No significant increase of late radiation complications has been observed in the radiochemotherapy arm.

In 2002, the Institute of Radiation Oncology Prague adopted a policy of treating patients with head and neck cancer with a weekly platinum chemotherapy concurrently with radiotherapy in the postoperative setting.

\section{Patients and Methods}

Aim of this study was to determine the efficacy of postoperative radiochemotherapy with weekly cisplatin in locoregionally advanced or high risk head and neck cancer in a single institutional setting. The endpoints included compliance and toxicity of radiochemotherapy, overall survival, locoregional control, time to progression and disease free survival.

Patients eligibility: Eligible patients had to have a previously untreated, histologically proven carcinoma arising from the head and neck area, with stage III/IV or tumors with positive or close $(\leq 5 \mathrm{~mm})$ resection margins, and no distant metastases. Patients were required to have an Karnofsky Performance Status $\geq 70 \%$ and adequate organ function (granulocyte count $\geq 1,5 \cdot 10^{9} / \mathrm{l}$, platelet count $\geq 100.10^{9} / \mathrm{l}$, hemoglobin $\geq 90 \mathrm{~g} / \mathrm{l}$, creatinine clearance $\geq 60 \mathrm{ml} / \mathrm{min}$ ). All patients signed informed consent forms approved by institutional review board.

Surgery: Primary surgical resection was performed for primary disease as well as clinically involved neck lymph nodes in all patients with radical intent. All patients with R0 (no residual disease), R1 (microscopic residual disease) and R2 (macroscopic residual disease) type of resection we included to the study. Time interval between surgery and radiotherapy had to be $\leq 120$ days.

Radiotherapy: All patients underwent treatment simulation in a supine position. Patient's fixation was achieved by use of individualized thermoplastic masks. All patients were treated with 5-6 MV photons from linear accelerators. The planned total dose was 70 Gy after R1/2 resection or 60 Gy (64 Gy with conformal radiotherapy and IMRT) after R0 resection to the known site of disease, in 2 Gy fractions delivered five times weekly.

Chemotherapy: Patients were scheduled to receive cisplatin $\left(40 \mathrm{mg} / \mathrm{m}^{2}\right)$ once a week, administered concurrently with radiation. All patients received prophylactic hydration and antiemetic agents. Prophylactic antiemetics consisted of setron antiemetics, dexamethasone and metoclopramide. Determination of hematological and renal parameters was performed before each chemotherapy cycle. The planned number of chemotherapy courses was 7 (in patiens with planned total dose of radiotherapy $70 \mathrm{~Gy}$ ) or 6 (planned total dose 60-64 Gy).

Supportive care:Feeding tube insertion was recommended before or at the beginning of treatment. Type of tube was depended on medici suitability. Percutaneous endoscopic gastrostomy tube was prefered. Defined enteral feeding was initiated, with a weight loss of 5\% from initial pretreatment weight. Prophylactic mouth washes were recommended. Radioprotection with subcutaneous amifostin was allowed when significant portion of both parotid glands were included in the radiation port (with exception of IMRT). Patients were hospitalized during the entire treatment with a possibility of release on weekends.

Treatment-related toxicity: Acute radiation toxicities were scored weekly using Radiation Therapy Oncology Group criteria, toxicities attributed to chemotherapy were graded according to the National Cancer Institute Common Toxicity Criteria. Toxicity assessment was repeated weekly throughout the whole course of radiochemotherapy. Late radiation toxicities were evaluated using the Radiation Therapy Oncology Group / European Organization for Research and Treatment of Cancer Late Radiation Morbidity Scoring Scheme $>90$ days after treatment end.

Follow-up: Patients were evaluated 4 weeks after completion of the whole treatment and then every 3 months for the first year, every 4 months for the next year, every 6 months for the next 3 years, and annually thereafter. Visits were performed alternately at the Institute of Radiation Oncology Prague by the otorhinolaryngologist and radiation oncologist and in a centre, where surgery was realized, by the head and neck surgeon.

Statistical analysis: The potential follow-up was calculated as the time between surgery and the closeout date (December 31, 2008) for all patients, regardless of vital status. All time-to-event analyses using the Kaplan-Meier product-limit method, with 95\% confidence intervals (CIs). Overall sur- 
vival (OS) was defined as the time to death from any cause. Locoregional control (LRC) was calculated as the time to the first local or regional recurrence. Time to progression (TTP) was defined as the time to the first local, regional or distant failure. Disease free survival (DFS) was defined as the time to a recurrence at any site or death from any cause. Univariate and multivariate logistic regression analysis were carried out to investigate the prognostic factors association with OS, LRC, TTP and DFS. A level of significance of $p<0,05$ was applied. For univariate analysis age, sex, smoking status, tumor site, stage, pT- classification, pN-classification, type of resection, lymphangio-/angioinvasion, perineural invasion, grading, surgery centre, interval between surgery and radiotherapy, total radiotherapy time, total dose of radiotherapy, number of chemotherapy cycles, weight loss during radiotherapy and duration of a feeding tube were analyzed.

\section{Results}

100 consecutive patients [WHO $\leq 2$, male to female ratio $84 / 16$, median age 54 years] with a histologically proven locally advanced or high risk carcinoma of the head and neck treated at the Institute of Radiation Oncology were included in this study between July 2002 and December 2008. The most frequent (49\%) diagnoses were tumors of the oropharynx. Stage IV was predominant (86\%). $84 \%$ patients were either current smokers or exsmokers. Daily consumption of alcohol was noted in $60 \%$ patients. The sociodemographic and tumorspecific characteristics of the patient population are presented in Table 1 and Table 2. The median duration of follow up at the time of analysis (December 2008) was 30 months (mean 35,2 , range, 7-83).

Type of surgery: Twelve centres referred patients to postoperative treatment with radiation. These centres included 4 university centre (64\% patients) and 8 departments of otorhinolaryngology in regional hospitals (36\% patients). All patients except five underwent primary resection of primary tumor and unilateral or bilateral neck dissection. In five patients surgical intervention was limited to resection of primary tumor without neck dissection. The most common type of neck dissection was unilateral comprehensive neck dissection (45\%), followed by unilateral selective neck dissection (23\%). Types of neck dissections are presented in Table 3.

The surgery with sufficient resection margins was detected in $58 \%$ patients. Median interval between surgery and radiotherapy was 54 days (range $19-119$ ), only $53 \%$ patients started treatment with radiochemotherapy $\leq 8$ weeks after surgery.

Compliance to radiochemotherapy: Median total dose of radiation was $66 \mathrm{~Gy}$ (range, 18-72). In $\mathrm{R} 0$ and $\mathrm{R} 1 / \mathrm{R} 2$ resection, median total dose was 64 Gy and 70 Gy, respectively. The radiation treatment techniques varied depending on the time period of treatment $-2 \mathrm{D}$ radiotherapy with two lateral opposite wedged fields and a direct posterior field with central shielding block protecting spinal cord $(n=36)$, conventional $3 \mathrm{D}$-conformal radiotherapy $(\mathrm{n}=40)$ and intensity
Table1. Demografic and clinical characteristics

\begin{tabular}{|c|c|}
\hline Age (median, range) [y] & $54(32-71)$ \\
\hline \multicolumn{2}{|c|}{$\operatorname{Sex}[\mathrm{n}=\%]$} \\
\hline Male & 84 \\
\hline Female & 16 \\
\hline \multicolumn{2}{|c|}{ Smoking history $[\mathrm{n}=\%]$} \\
\hline Smoker or exsmoker $<5$ years & 67 \\
\hline Exsmoker $\geq 5$ years & 17 \\
\hline Never & 13 \\
\hline Unknown & 3 \\
\hline \multicolumn{2}{|c|}{ Consumption of alcohol $[\mathrm{n}=\%]$} \\
\hline Daily & 60 \\
\hline Occasional & 33 \\
\hline Abstinence & 5 \\
\hline Unknown & 2 \\
\hline \multicolumn{2}{|c|}{ Primary site $[\mathrm{n}=\%]$} \\
\hline Oropharynx & 49 \\
\hline Larynx & 24 \\
\hline Oral cavity & 11 \\
\hline Hypopharynx & 10 \\
\hline Others & 6 \\
\hline \multicolumn{2}{|c|}{ Stage $[\mathrm{n}=\%]$} \\
\hline I & 2 \\
\hline II & 2 \\
\hline III & 10 \\
\hline IVA & 81 \\
\hline IVB & 5 \\
\hline \multicolumn{2}{|c|}{ Histological type $[\mathrm{n}=\%]$} \\
\hline Squamous cell carcinoma & 93 \\
\hline Undifferentiated carcinoma & 4 \\
\hline Adenoid-cystic carcinoma & 2 \\
\hline Transitional-cell carcinoma & 1 \\
\hline \multicolumn{2}{|c|}{ Grading $[\mathrm{n}=\%]$} \\
\hline Well differentiated & 5 \\
\hline Moderately differentiated & 33 \\
\hline Poorly differentiated & 50 \\
\hline Unknown & 2 \\
\hline \multicolumn{2}{|c|}{ Type of resection [n $=\%]$} \\
\hline R0 & 58 \\
\hline Close margins $\leq 5 \mathrm{~mm}$ & 9 \\
\hline $\mathrm{R} 1$ & 21 \\
\hline $\mathrm{R} 2$ & 10 \\
\hline Unknown & 2 \\
\hline \multicolumn{2}{|c|}{ Centre of surgery $[\mathrm{n}=\%]$} \\
\hline University centre & 64 \\
\hline Regional hospital & 36 \\
\hline
\end{tabular}

Table 2. T-, N- classification

\begin{tabular}{cccccc}
\hline $\mathrm{n}=\%$ & $\mathrm{~T} 1$ & $\mathrm{~T} 2$ & $\mathrm{~T} 3$ & $\mathrm{~T} 4$ & Total \\
\hline $\mathrm{N} 0$ & 2 & 2 & 4 & 14 & 22 \\
$\mathrm{~N} 1$ & 1 & 3 & 2 & 7 & 13 \\
$\mathrm{~N} 2$ & 8 & 16 & 21 & 16 & 61 \\
$\mathrm{~N} 3$ & 1 & 2 & 1 & 0 & 4 \\
Total & 12 & 23 & 28 & 37 & 100 \\
\hline
\end{tabular}


modulated radiotherapy $(\mathrm{n}=24) .96 \%$ patients received the full radiation treatment as planned.One patient's treatment was stopped after $68 \mathrm{~Gy}$ due to high grade of skin toxicity, another 3 patients decided to discontinue treatment after 16,36 and $68 \mathrm{~Gy}$ for personal motives. In $25 \%$ patients the total treatment time was prolonged for more than 3 days. In total, 461 courses concomitant chemotherapy were applied. Median number of chemotherapy courses was 5 (range, 18 ). Of the 100 patients, 59 received at least five courses, and

Table 3. Types of neck dissections

\begin{tabular}{ll}
\hline Type of neck dissection (ND) & $\mathrm{n}=\%$ \\
\hline Unilateral radical ND & 45 \\
Unilateral selective ND & 23 \\
Unilateral radical + contralateral selective ND & 13 \\
Bilateral selective ND & 12 \\
Bilateral radical ND & 2 \\
Without ND & 5 \\
Total & 100 \\
\hline
\end{tabular}

Table 4. Reasons for a termination of concomitant chemotherapy

\begin{tabular}{ll}
\hline Reason & $\mathrm{n}=\%$ \\
\hline Hematological toxicity & 34 \\
Renal toxicity & 17 \\
Gastrointestinal toxicity & 7 \\
In-field radiation toxicity & 5 \\
Fatigue & 5 \\
Infection & 3 \\
Refusal & 6 \\
All courses of chemotherapy & 23 \\
Total & 100 \\
\hline
\end{tabular}

only 29 received at least six courses of chemotherapy. The most frequent reason for a early cessation of concomitant chemotherapy were hematological toxicities (34\%). Other arguments are listed in Table 4.

Acute toxicity: Acute mucositis Grade 3/4 was reported in $32 \%$, acute dermatitis Grade 3/4 in $18 \%$. Two cases of laryngeal toxicity with necessity to accomplish tracheostomy were recorded. Median weight loss during the treatment was $7 \mathrm{~kg}$ ( $10 \%$ of the pretreatment weight). $40 \%$ of patients were fully dependent on a nutritional support with a feeding tube in some part of treatment, $40 \%$ were able to swallow liquid at most. Only 8 patients were able to eat solid diet during the all treatment course. Hematological toxicities were relatively frequent, Grade 3/4 neutropenia occured in 19\%. Three cases of febrile neutropenia were recorded. Renal toxicity and emetic potential of cisplatin were mild in general. No death was observed during the treatment. Table 5 summarizes the acute toxicities of the treatment.

Late toxicity: Late toxicities were mild, predominantly subcutaneous fibrosis and xerostomia. $60 \%$ of patients were able to eat solid diet 1 year after the treatment, 2 patients had afagia requiring permanent feeding tube. 6 cases of osteoradionecrosis of the mandible were reported during the follow-up 5-61 months after radiochemotherapy. All cases of osteoradionecrosis occured in patients who had received 70 Gy. One case was treated conservatively with hyperbaric oxygen therapy, five cases of osteoradionecrosis were treated surgically. Table 6 summarizes the late toxicities of the treatment.

Overall survival: Twenty nine of the 100 patients died at the time of analysis. 12 of them died of recurrent or progressive disease, 3 died of progressive second primary tumors, and 14 died because of comorbidity. The estimated two and half year overall survival was $64 \%$ (95\% CI 52-75\%, Figure 1). On univariate analysis, parameters predictive of overall survival were

Table 5. Acute toxicities

\begin{tabular}{|c|c|c|c|c|c|c|c|c|}
\hline Grade & $\begin{array}{l}\text { mucous membrane } \\
(\%)\end{array}$ & $\begin{array}{l}\text { skin } \\
(\%)\end{array}$ & $\begin{array}{l}\text { salivary gland } \\
(\%)\end{array}$ & $\begin{array}{l}\text { eye } \\
(\%)\end{array}$ & $\begin{array}{l}\text { ear } \\
(\%)\end{array}$ & larynx (\%) & pharynx (\%) & upper GI (\%) \\
\hline 0 & 0 & 2 & 4 & 89 & 78 & 57 & 8 & 0 \\
\hline I & 8 & 31 & 37 & 9 & 11 & 31 & 12 & 14 \\
\hline II & 60 & 49 & 59 & 2 & 11 & 7 & 40 & 68 \\
\hline III & 30 & 13 & - & 0 & 0 & 3 & 39 & 18 \\
\hline IV & 2 & 5 & 0 & 0 & 0 & 2 & 1 & 0 \\
\hline
\end{tabular}

\begin{tabular}{|c|c|c|c|c|c|c|}
\hline Grade & $\begin{array}{c}\text { leukocytes } \\
(\%)\end{array}$ & granulocytes (\%) & hemoglobin (\%) & $\begin{array}{c}\text { platelets } \\
(\%)\end{array}$ & $\begin{array}{c}\text { renal } \\
(\%)\end{array}$ & $\begin{array}{c}\text { vomiting } \\
(\%)\end{array}$ \\
\hline 0 & 17 & 34 & 28 & 77 & 43 & 67 \\
\hline I & 20 & 23 & 49 & 21 & 44 & 19 \\
\hline II & 33 & 24 & 20 & 1 & 13 & 12 \\
\hline III & 23 & 16 & 3 & 0 & 0 & 2 \\
\hline IV & 7 & 3 & 0 & 1 & 0 & 0 \\
\hline
\end{tabular}




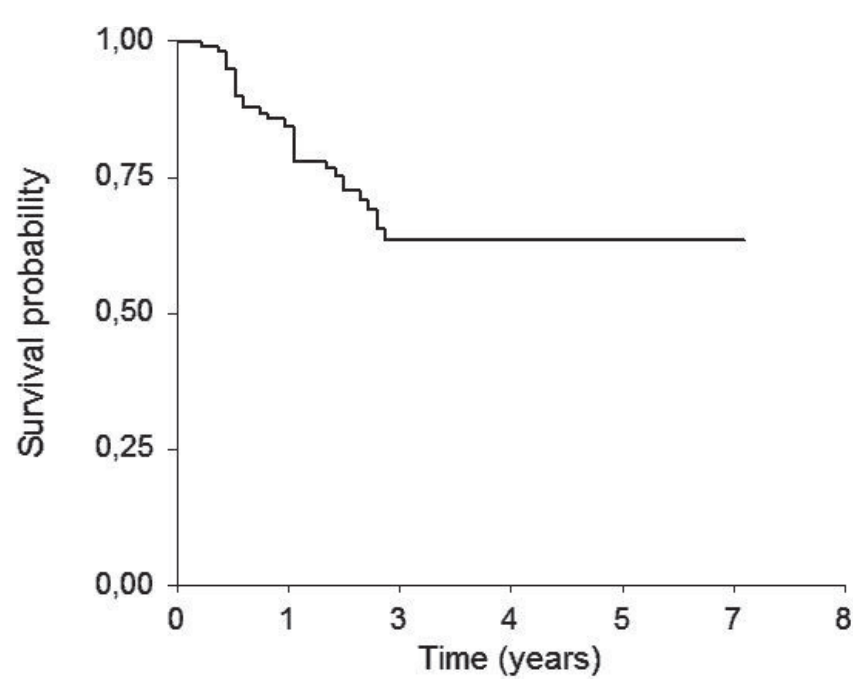

Figure1. Kaplan-Meier estimate of overall survival

male sex ( $\mathrm{p}=0,042)$, smoking history $(\mathrm{p}=0,017), \geq 2$ positive lymph nodes $(\mathrm{p}=0,009)$, stage IV $(\mathrm{p}=0,010)$, primary surgery in regional center $(\mathrm{p}=0,004)$.

Locoregional control: At analysis, 10 cases of locoregional failure were detected (6 local, 2 regional, 2 both local and regional), all but one were observed in patients with initial stage IV. Of note, only two patients underwent salvage surgery. The median time of detection of a recurrence was 13 months from surgery (range, 5-62). The majority of locoregional failure was detected up to 2 years after treatment $(80 \%)$. The estimated two and half year locoregional control rate was $88 \%$ (95\% CI $80-96 \%$, Figure 2). On univariete analysis, the parameter predictive of locoregional control was the presence of lymphangio-/angioinvasion $(\mathrm{p}=0,048)$.

Time to progression: At analysis, 8 patients experienced a distant failure (all with stage IV). The median time of detection of a distant metastasis was 19 months from surgery (range, 6-33). The majority of distant failures was detected up to 2 years after treatment $(75 \%)$. The lung metastases were the most common (63\%). The estimated two and half year time to progression was 79\% (95\% CI 69-89\%, Figure 3). On univariete analysis, parameters predictive of time to progression were $\geq 2$ positive lymph nodes $(\mathrm{p}=0,025)$, lymphangio-/angioinvasion $(\mathrm{p}=0,008)$ and perineural invasion $(\mathrm{p}=0,022)$.

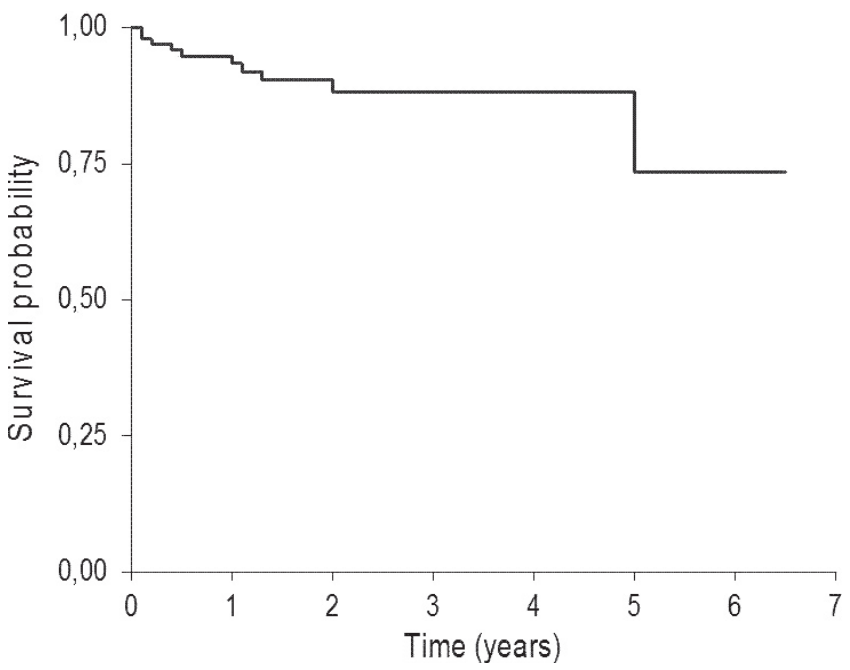

Figure 2. Kaplan-Meier estimate of locoregional control

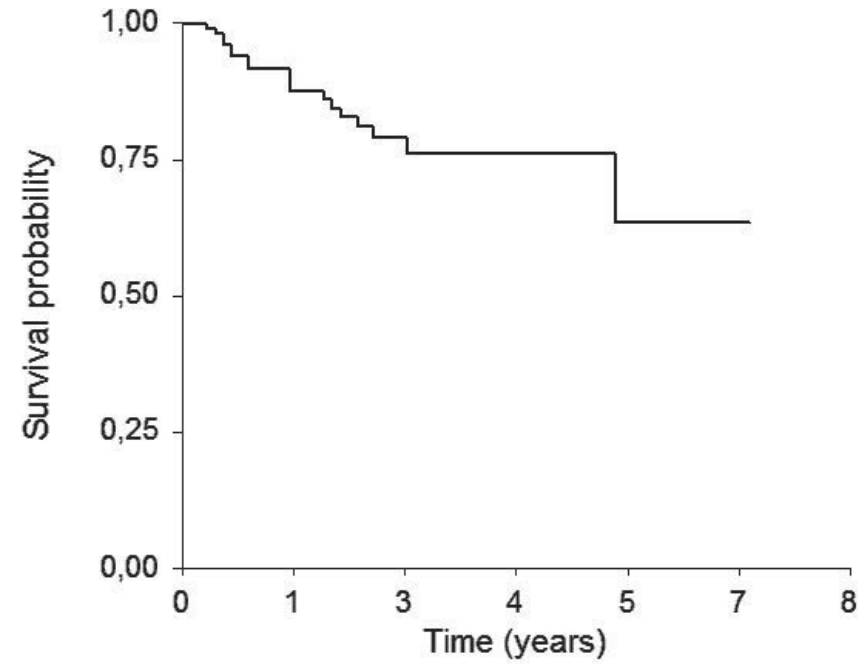

Figure 3. Kaplan-Meier estimate of time to progression

Disease free survival: The estimated two and half year disease free survival was 59\% (95\% CI 47-70\%. Figure 4). On univariete analysis, parameters predictive of disease free survival were smoking history $(\mathrm{p}=0,007), \geq 2$ positive lymph nodes

Table 6. Late toxicities

\begin{tabular}{ccccccccc}
\hline Grade & $\begin{array}{c}\text { mucous membrane } \\
(\%)\end{array}$ & skin (\%) & $\begin{array}{c}\text { subcuta-neous tissue } \\
(\%)\end{array}$ & $\begin{array}{c}\text { salivary gland } \\
(\%)\end{array}$ & $\begin{array}{c}\text { eye } \\
(\%)\end{array}$ & $\begin{array}{c}\text { larynx (\%) } \\
\text { brain } \\
(\%)\end{array}$ & $\begin{array}{c}\text { spinal cord (\%) } \\
\text { (\%) }\end{array}$ \\
\hline I & 31 & 12 & 24 & 8 & 98 & 84 & 98 & 95 \\
II & 62 & 85 & 40 & 54 & 0 & 14 & 2 \\
III & 7 & 3 & 30 & 32 & 2 & 2 & 0 & 0 \\
IV & 0 & 0 & 6 & 6 & 0 & 0 & 0 \\
\hline
\end{tabular}




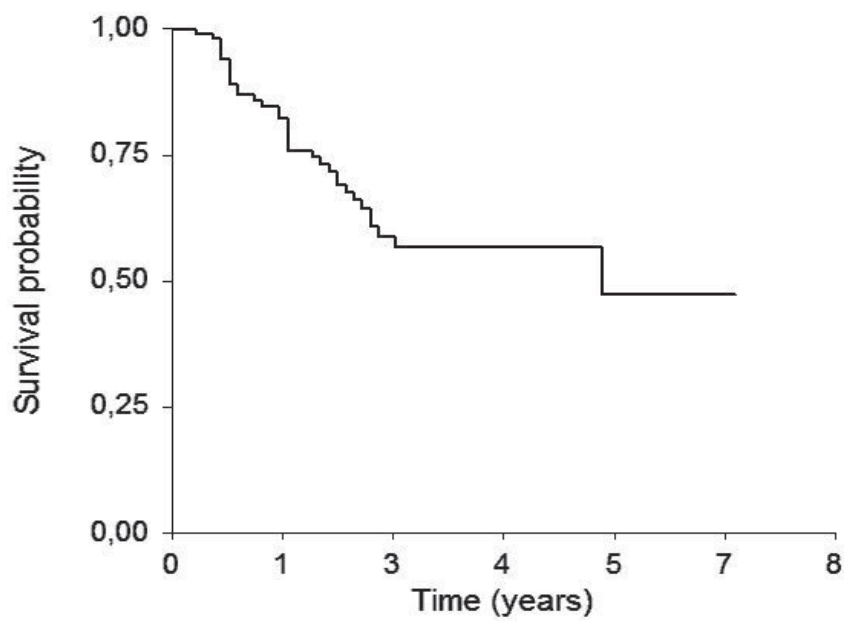

Figure 4. Kaplan-Meier estimate of disease free survival

$(\mathrm{p}=0,009)$, stage IV $(\mathrm{p}=0,019)$, primary surgery in a regional centre $(p=0,047)$. Three second primary tumors were recorded during the follow-up (lung cancer 1, oesophageal melanoma 1 , cancer of stomach 1).

Multivariete analysis: In multivariete analysis, primary surgery in the university centre was an independent positive prognostic factor for overall survival ( $\mathrm{p}=0,012$, RR 2,73; 95\% CI 1,25-5,97, Figure 5).

\section{Discussion}

Radical surgery and postoperative radiation therapy have been the traditional standards of therapy for patients with locoregionally advanced carcinoma of the head and neck for many years. Recently, the policy of postoperative radiochemotherapy was adopted in an attempt to improve treatment outcomes. Randomized trials testing chemotherapy, in addition to surgery and radiation, showed benefit in terms of locoregional control or survival. Three major postoperative trials with radiochemotherapy were published - EORTC 22931, RTOG 9501 and ARO 96-3 [13-15]. All these trials differed in eligibility criteria. EORTC trial evaluated patients with pT3/pT4 tumors or patients with $\mathrm{pT} 1 / \mathrm{pT} 2$ tumors and some risk factor (multiple positive neck nodes, insufficient resection margins, perineural involvement, vascular embolism, extracapsular extension in neck nodes). RTOG trial evaluated patients with extracapsular spread in neck nodes or insufficient surgical margins or multiple positive neck nodes. Finally, the ARO trial randomized patients with pT3 tumors and insufficient resection margins or patients with pT4 tumors or patients with multiple positive neck nodes or extracapsular extension in neck nodes. Whereas EORTC and RTOG trials used three-weekly cisplatin in monotherapy, the ARO trial tested the combination of three-weekly cisplatin and 5 -fluorouracil. Differences in eligibility criteria and treatment explain the differences in the outcome in the trials.

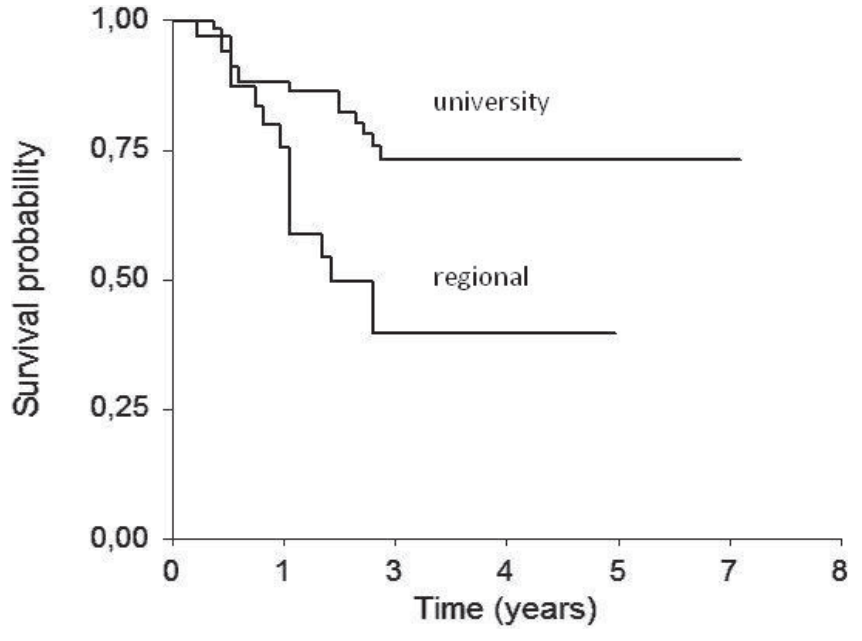

Figure 5. Kaplan-Meier estimate of overall survival according to a centre

The aim of this paper was to report the results of adding monochemotherapy with cisplatin to surgery and radiation. In contrast to the EORTC, RTOG and ARO trials, we used a weekly cisplatin schedule at a dose of $40 \mathrm{mg} / \mathrm{m}^{2}$. We decided to use a weekly schedule on the basis of the large experience in other malignancies.

The compliance with radiotherapy was excellent. Only one patient did not complete the planned dose of radiotherapy due to acute toxicity. At the other site, the compliance with chemotherapy was poor. Chemotherapy completion rates were $49 \%, 61 \%$, and $73 \%$ in the RTOG, EORTC and ARO studies, respectively. In our study only $29 \%$ patiens completed at least six courses of weekly cisplatin. The main reason for a discontinuation of chemotherapy was high number of hematological toxicities associated with a weekly administration of cisplatin.

One of the most significant problems of the combination of chemotherapy and radiotherapy is the increase of radiation toxicity. With the regimen used in our study, severe acute radiation was acceptable and no treatment-related deaths occurred. The rate of severe mucositis Grade III/IV (32\%) was lower than the results in experimental arms of published randomised trials with three-weekly cisplatin (RTOG $41 \%$, EORTC $44.5 \%$ ). We recorded six cases of osteoradionecrosis of the mandible during the follow-up. It was higher than presumptive rate. Higher rate of osteoradionecrosis in our population can be result of an increasing dose of radiotherapy. All patients with osteonecrosis received 70 Gy of radiation.

Most patients in our study had unfavourable characteristics, including the advanced stage, positive or close margins, and more than one positive lymph nodes. Despite these, with regard to limited follow-up, the outcomes were comparable with outcomes of experimental arms of published randomised trials. 2 year overall survival were $64 \%$ and $71 \%$ in RTOG and EORTC trial, respectively (in our study $64 \%$ in 2.5 years), 
2 year locoregional control was $60 \%$ and $78 \%$ (in our study $88 \%$ in 2.5 years), 2 year disease free survival was $54 \%$ and $63 \%$ (in our study $59 \%$ in 2.5 years).

A number of pathologic adverse risk factors have been associated with higher recurrence rates after surgery, including positive margins of resection [20-21]. Data from EORTC and RTOG trials have substantiated that positive resection margins and extracapsular spread in neck nodes where the most significant adverse prognostic factors [22].In some retrospective studies [23-25], a dose-effect relationship was found in cases of positive margins. In our study surgical margin status was not found to be an important prognostic factor in regards to locoregional control or survival. We can estimate that higher dose of radiotherapy in $\mathrm{R}+$ resections (70 Gy) decreases the risk of a recurrence in this type of resection.

Several studies referred the impact of a prolonged interval between surgery and postoperative radiotherapy on a prognosis [26-27]. Protracted waiting time on radiotherapy is associated with significantly lower locoregional control and overall survival. In our study, where one half of patients began radiochemotherapy $>8$ weeks after surgery, interval between resection and postoperative radiochemotherapy was not found to be an important prognostic factor related to locoregional control or survival. We presume that protraction of this interval in the presence of concomitant chemotherapy is not detrimental.

Several papers reported on the relationship between treating institution and treatment outcomes in different localities of cancer. However, reports from the area of head and neck cancer are rare [28-30]. In the present study, surgery was performed in university centres or regional hospitals and there was some indication that survival was higher in patients from university centres than from other hospitals. Interestingly, the type of a treating institution was independently of postoperative radiochemotherapy outcomes, a finding not reported previously. We have no clear explanation for this finding. Percentage of patients with sufficient resection margins was only slightly different between these two groups of centres (regional hospitals 55\%, university centres 58\%), similarly, the percentage of locoregional recurrences was analogous between these two groups (regional hospitals 9\%, university centres $10 \%)$. Our study shows, that treatment centre was independent prognostic factor for survival not for locoregional control. Percentage of deaths associated with a progression of tumors was equal between the two groups (both $12 \%$ ), consequently the differences were in distribution of deaths associated with comorbid illnesses. We hypothesize, that patients treated at regional hospitals mostly come from countryside, where autodestructive lifestyle with high consumption of tobacco and alcohol are more prevalent compared to metropolitans. With regard to frequent comorbidities in patients with head and neck cancer, active role could play a lower availibility of medical care in countryside.

Conclusion. Postoperative radiotherapy with weekly cisplatin is toxic, but tolerable and highly active in terms of lo- coregional control and survival. The impact of a surgical centre was the most important in association with overall survival.

The best radiochemotherapy regimen still needs to be determined to optimize the therapeutic index and reduce the risk of both locoregional and distant failure.

\section{References}

[1] MUNRO AJ. An overview of randomized controlled trials of adjuvant chemotherapy in head and neck cancer. Br J Cancer 1995, 71, 83-91. http://dx.doi.org/10.1038/bjc.1995.17

[2] EL-SAYED S, NELSON N. Adjuvant and adjunctive chemotherapy in the management of squamous cell carcinoma of the head and neck region: A meta-analysis of prospective and randomized trials. J Clin Oncol 1996, 14, 838-847.

[3] PIGNON J, BOURHIS J, DOMENGE C, DESIGNÉ L. Chemotherapy added to locoregional treatment for head and neck squamous cell carcinoma: Three meta-analysis of updated individual data. Lancet 2000, 355, 949-955.

[4] BROWMAN GP, HODSON DI, MACKENZIE RJ, BESTIC $\mathrm{N}$, ZURAW L. Choosing a concomitant chemotherapy and radiotherapy regimen for squamous cell head and neck cancer: A systematic review of the published literature with subgroup analysis. Head Neck 2001, 23, 579-589. http://dx.doi. org/10.1002/hed.1081

[5] LANGENDIJK JA, LEEMANS CR, BUTER J, BERKHOF J, SLOTMAN BJ. The additional value of chemotherapy to radiotherapy in locally advanced nasopharyngeal carcinoma: a meta-analysis of the published literature. J. Clin. Oncol.2004, 22, 4604-4612. http://dx.doi.org/10.1200/ JCO.2004.10.074

[6] BUDACH W, HEHR T, BUDACH V, BELKA C, DIETZ K. A meta-analysis of hyperfractionated and accelerated radiotherapy and combined chemotherapy and radiotherapy regimens in unresected locally advanced squamous cell carcinoma of the head and neck. BMC Cancer 2006, 6, 28. http://dx.doi.org/10.1186/1471-2407-6-28

[7] AMDUR RJ, PARSONS JT, MENDENHALL WM, MILLION RR, STRINGER SP, et al. Postoperative irradiation for squamous cell carcinoma of the head and neck: an analysis of treatment results and complications. Int JRadiat Oncol Biol Phys 1989, 16, 25-36. http://dx.doi.org/10.1016/03603016(89)90006-0

[8] TUPCHONG L, SCOTT CB, BLITZER PH, MARCIAL VA, LOWRY LD, et al. Randomized study of preoperative versus postoperative radiation therapy in advanced head and neck carcinoma: Long-term follow-up of RTOG study 73-03. Int J Radiat Oncol Biol Phys 1991, 20, 21-28. http://dx.doi. org/10.1016/0360-3016(91)90133-O

[9] PETERS LJ, GOEPFERT H, ANG KK, BYERS RM, MAOR $\mathrm{MH}$, et al. Evaluation of the dose for postoperative radiation therapy of head and neck cancer: first report of a prospective randomized trial. Int J RadiatOncol Biol Phys 1993, 26, 3-11. http://dx.doi.org/10.1016/0360-3016(93)90167-T

[10] The Department of Veterans Affairs Laryngeal Cancer Study Group. Induction chemotherapy plus radiation compared with surgery plus radiation in patients with advanced laryn- 
geal cancer. N Engl J Med 1991, 324, 1685-1690. http://dx.doi. org/10.1056/NEJM199106133242402

[11] LEFEBVRE JL, CHEVALIER D, LUBOINSKI B, KIRKPATRICK A, COLLETTE L, et al. Larynx preservation in pyriform sinus cancer: Preliminary results of a European Organization for Research and Treatment of Cancer phase III trial - EORTC Head and Neck Cancer Cooperative Group. J Natl Cancer Inst 1996, 88, 890-899. http://dx.doi.org/10.1093/ inci/88.13.890

[12] PACCAGNELLA A, ORLANDO A, MARCHIORI C, ZORAT PL, CAVANIGLIA G, et al. Phase III trial of initial chemotherapy in stage III or IV head and neck cancers: a study by the Gruppo di Studio sui Tumori della Testa e del Collo. J Natl Cancer Inst 1994, 86, 265-272. http://dx.doi. org/10.1093/jnci/86.4.265

[13] BERNIER J, DOMENGE C, OZSAHIN M, MATUSZEWSKA K, LEFĖBVRE JL, et al. Postoperative irradiation with or without concomitant chemotherapy for locally advanced head and neck cancer. N Engl J Med 2004, 350, 1945-1952. http://dx.doi.org/10.1056/NEJMoa032641

[14] COOPER JS, PAJAK TF, FORASTIERE AA, JACOBS J, CAMPBELL BH, et al. Postoperative concurrent radiotherapy and chemotherapy for high-risk squamous-cell carcinoma of the head and neck. N Engl J Med 2004, 350, 1937-1944. http://dx.doi.org/10.1056/NEJMoa032646

[15] FIETKAU R, LAUTENSCHLÄGER C, SAUER R, DUNST J BECKER A, et al. Postoperative concurrent radiochemotherapy versus radiotherapy in high-risk SCCA of the head and neck: results of the German phase III trial ARO 96-3. J Clin Oncol 2006, 24, Abstract 5507.

[16] HAFFTY BG, SON YH, PAPAC R, SASAKI CT, WEISSBERG JB, et al. Chemotherapy as an adjunct to radiation in the treatment of squamous cell carcinoma of the head and neck: Results of the Yale Mitomycin Randomized Trials. J Clin Oncol 1997, 15, 268-276.

[17] ZAKOTNIK B, BUDIHNA M, SMID L, SOBA E, STROJAN $\mathrm{P}$, et al. Patterns of failure in patients with locally advanced head and neck cancer treated postoperatively with irradiation or concomitant irradiation with Mitomycin C and Bleomycin. Int J Radiat Oncol Phys 2007, 67, 685-690. http://dx.doi. org/10.1016/j.ijrobp.2006.09.018

[18] WINQUIST E, OLIVER T, GILBERT R. Postoperative chemoradiotherapy for advanced squamous cell carcinoma of the head and neck: A systematic review with meta-analysis. Head Neck 2007, 29, 38-46. http://dx.doi.org/10.1002/hed.20465

[19] BACHAUD JM, COHEN-JONATHAN E, ALZIEU C, DAVID JM, SERRANO E, et al. Combined postoperative radiotherapy and weekly cisplatin infusion for locally advanced head and neck carcinoma: final report of a randomized trial. Int J Radiat Oncol Biol Phys 1996, 36, 999-1004. http://dx.doi. org/10.1016/S0360-3016(96)00430-0

[20] COOPER JS, PAJAK TF, FORASTIERE A, JACOBS J, FU KK, et al. Precisely definic high-risk operable head and neck tumors based on RTOG\#85-03 and \#88-24: targets for postoperative radiochemotherapy? Head Neck 1998, 20, 588-594. http://
dx.doi.org/10.1002/(SICI)1097-0347(199810)20:7<588::AIDHED2>3.0.CO;2-F

[21] LARAMORE GE, SCOTT CB, SCHULLER DE, HASELOW RE, ERVIN TJ, et al. Is a surgical resection leaving positive margins of benefit to the patient with locally advanced squamous cell carcinoma of the head and neck: a comparative study using the intergroup study 0034 and the Radiation Therapy Oncology Group head and neck database. Int J Radiat Oncol Biol Phys 1993, 27, 1011-1016. http://dx.doi. org/10.1016/0360-3016(93)90517-Y

[22] BERNIER J, COOPER JS, PAJAK TF, VAN GLABBEKE M, BOURHIS J, et al. Defining risk levels in locally advanced head and neck cancers: a comparative analysis of concurrent postoperative radiation plus chemotherapy trials of the EORTC (\#22931) and RTOG (\# 9501). Head Neck 2005, 27, 843-850. http://dx.doi.org/10.1002/hed.20279

[23] ZELEFSKY MJ, HARRISON LB, ARMSTRONG JG. Longterm treatment results of postoperative radiation therapy for advanced stage oropharyngeal carcinoma. Cancer 1992, 70, 2388-2395. http://dx.doi.org/10.1002/1097-0142(19921115) 70:10<2388::AID-CNCR2820701003>3.0.CO;2-M

[24] SMEELE LE, LEEMANS CR, LANGENDIJK JA, TIWARI $\mathrm{R}$, SLOTMAN BJ, et al. Positive surgical margins in neck dissection specimens in patients with head and neck squamous cell carcinoma and the effect of radiotherapy. Head Neck 2000, 22, 559-563. http://dx.doi.org/10.1002/10970347(200009)22:6<559::AID-HED3>3.0.CO;2-7

[25] PFREUNDNER L, WILLNER J, MARX A, HOPPE F, BECKMANN G, et al. The influence of the radicality of resection and dose of postoperative radiation therapy on local control and survival in carcinomas of the upper aerodigestive tract. Int J Radiat Oncol Biol Phys 2000, 47, 1287-1297. http://dx.doi. org/10.1016/S0360-3016(00)00514-9

[26] ANG KK, TROTTI A, BROWN BW, GARDEN AS, FOOTE $\mathrm{RL}$, et al.: Randomized trial adressing risk features and time factors of surgery plus radiotherapy in advanced head-andneck cancer. Int J Radiat Oncol Biol Phys 2001, 51, 571-578. http://dx.doi.org/10.1016/S0360-3016(01)01690-X

[27] HUANG J, BARBERA L, BROUWERS M, BROWMAN G, MACKILLOP WJ. Does delay in starting treatment affect the outcomes of radiotherapy? A systematic review. J Clin Oncol 2003, 21, 555-563. http://dx.doi.org/10.1200/ LCO.2003.04.171

[28] STILLER CA, PASSMORE SJ, KROLL ME, BROWNBILL PA, WALLIS JC, et al. Patterns of care and survival for patients aged under 40 years with bone sarcoma in Britain, 1980-1994. Br J Cancer 2006, 94, 22-29.

[29] HERMANEK P, WIEBELT H, RIEDL S, STAIMMER D, HERMANEK P. Long-term results of surgical therapy of colon cancer. Results of the Colorectal Cancer Study Group. Chirurg. 1994, 65, 287-297.

[30] CHEUNG MC, KONIARIS LG, PEREZ EA, MOLINA MA, GOODWIN WJ, et al. Impact of Hospital Volume on Surgical Outcome for Head and Neck Cancer. Ann Surg Oncol 2009, 16, 1001-1009. http://dx.doi.org/10.1245/s10434-008-0191-9 